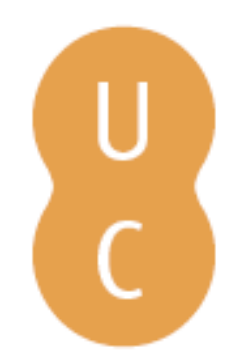

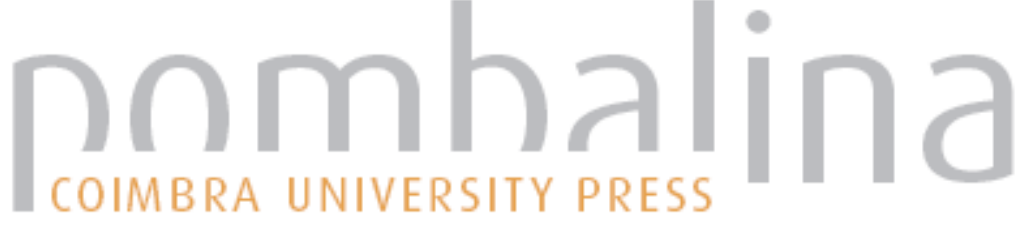

\section{Nas margens da modernidade: duas abordagens da história}

\author{
Autor(es): $\quad$ Mortimer, Junia
}

Publicado por: Imprensa da Universidade de Coimbra

URL

persistente: URI:http://hdl.handle.net/10316.2/36666

DOI: $\quad$ DOI:http://dx.doi.org/10.14195/978-989-26-1015-3_4

Accessed : $\quad$ 26-Apr-2023 00:41:06

A navegação consulta e descarregamento dos títulos inseridos nas Bibliotecas Digitais UC Digitalis, UC Pombalina e UC Impactum, pressupõem a aceitação plena e sem reservas dos Termos e Condições de Uso destas Bibliotecas Digitais, disponíveis em https://digitalis.uc.pt/pt-pt/termos.

Conforme exposto nos referidos Termos e Condições de Uso, o descarregamento de títulos de acesso restrito requer uma licença válida de autorização devendo o utilizador aceder ao(s) documento(s) a partir de um endereço de IP da instituição detentora da supramencionada licença.

Ao utilizador é apenas permitido o descarregamento para uso pessoal, pelo que o emprego do(s) título(s) descarregado(s) para outro fim, designadamente comercial, carece de autorização do respetivo autor ou editor da obra.

Na medida em que todas as obras da UC Digitalis se encontram protegidas pelo Código do Direito de Autor e Direitos Conexos e demais legislação aplicável, toda a cópia, parcial ou total, deste documento, nos casos em que é legalmente admitida, deverá conter ou fazer-se acompanhar por este aviso.

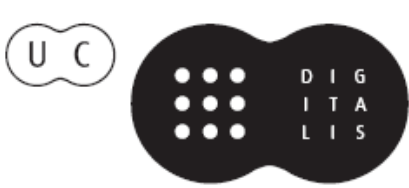


IMPRENSA DA

UNIVERSIDADE

DE COIMBRA

COIMBRA

UNIVERSITY

PRESS

\section{NA GÉNESE DAS RACIONALIDADES MODERNAS II}

Em torno de Alberti e do Humanismo

MÁRIO KRÜGER et alii

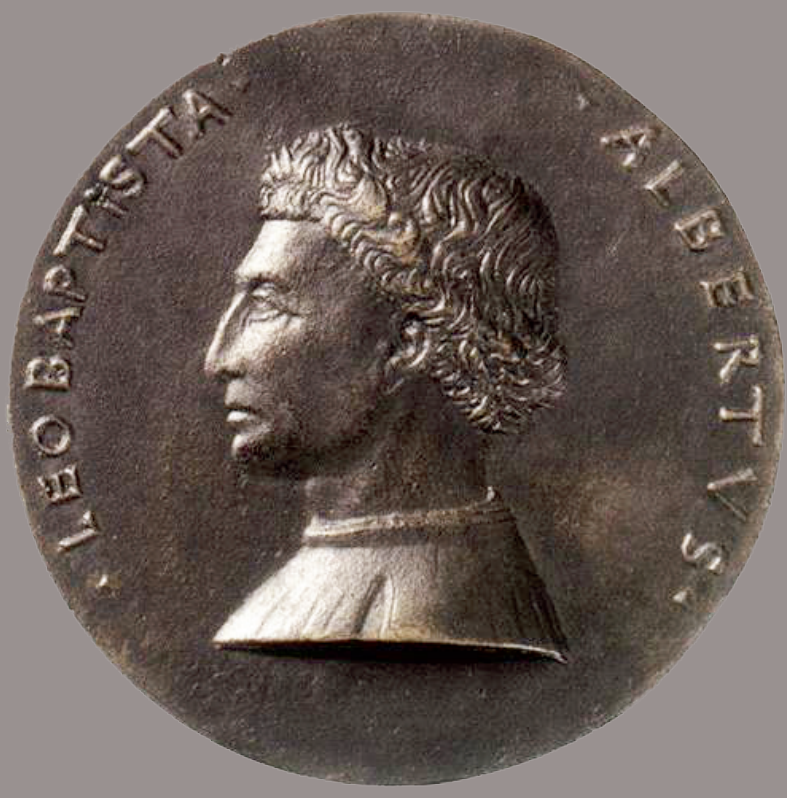




\section{NAS MARGENS DA MODERNIDADE DUASABORDAGENS DA HISTÓRIA}

Junia Mortimer

\section{Resumo}

Este artigo ${ }^{99}$ propõe um diálogo entre o conceito de bistoria no texto Da Pintura (1435 - trad. 1992) de Leon Battista Alberti e a ideia de pós-história, na sua abordagem proposta para a arquitetura segundo Anthony Vidler, no seu livro "Histórias do Presente Imediato". Em que medida essas compreensões da história se relacionam e onde se diferenciam? Desse embate resulta uma atualidade crítica do pensamento de Alberti no sentido de que ele fomenta a liberdade da história como narrativa, para a pintura e a arquitetura. Porém, ele a restringe a uma natureza mítica. Esse território exclusivamente mítico difere de uma abordagem contemporânea, como a de Vidler, na qual o autor reclama por uma revisão crítica dos ícones modernistas, nas quais as narrativas míticas talvez contribuam para manter não solucionados os problemas não resolvidos ou para manter ecoando as questões ainda abertas da modernidade. História da arquitetura; Projeto; História; Renascimento; Alberti; Pós-história; Anthony Vidler.

${ }^{99}$ Este artigo é fruto das discussões desenvolvidas no grupo "Arquitetura, Humanismo e República", coordenado pelo professor Carlos Antônio Leite Brandão. Agradeço à agência de fomento FAPEMIG que financia, por meio de bolsa de doutorado, o desenvolvimento de meus trabalhos de pesquisa. Agradeço também à orientação do professor Stéphane Huchet, em discussões que contribuíram indiretamente no desenrolar deste trabalho. 


\section{Résumé}

Cet article propose un dialogue entre le concept d'historia dans le texte De La Peinture (1435/ trad.1992) de Leon Battista Alberti e l'idée de post-histoire, selon l'approche présentée par Anthony Vidler, dans son texte Histories of the Immediate Present (2008). Dans quel sens ces compréhensions de l'histoire, par rapport à l'art et à l'architecture, se rapprochent et dans quelle mesure elles se diffèrent, si on considère la distance temporel que les sépare? De ce combat il résulte une atualité critique de la pensée d'Alberti au sens ou il promeuve la liberté de l'histoire en tant que narrative, pour la peinture autant que pour l'architecture. Cependant Alberti restreindre cette narrative à un territoire mythique. Cela le diffère d'une approche contemporaine, comme celui de Vidler, dans laquelle l'auteur propose une révision critique des icônes modernes, à fin de stimuler les solutions des problèmes toujours pas résolus et les questions toujours sans réponse dans l'histoire de la modernité. Histoire d'Architecture; Projet; Histoire; Renascimento; Alberti; Post-histoire; Anthony Vidler.

\section{Abstract}

This paper proposes a dialogue between the concept of "history" in the text of 1435, "On Painting", by Leon Battista Alberti, and the idea of post-history in its proposed approach to architecture, according to Anthony Vidler, in his book Histories of the Immediate Present (2012). The question which arises from this confrontation is: to what extent these understandings of history relate to each other and where they differ? This confrontation results in a critical atuality of some of Alberti's ideas on history in the sense that he forsters the freedom of history as a narrative. However, he restricts history to within the limits of mythical narrative. This approach is distinct of a contemporary approach as that proposed by Anthony Vidler, as Vidler stimulates the search for the unsolved problems of modernity, to which we have to respond today in contemporary cities. History of architecture; Design; History; Renaissance; Alberti; Anthony Vidler. 
What has been the influence of contemporary architectural bistorians on the bistory of contemporary architecture?

Reyner Banham,

“The New Brutalism”, Architectural Review, December 1955.

O que me traz ao congresso é a proposta de realizar um diálogo entre o conceito de historia, para a pintura e a arquitetura, como está no texto Da Pintura, de Leon Battista Alberti (título original Ut Pictura, de $1435^{100}$ ) e a ideia de pós-história, na sua abordagem proposta para a arquitetura segundo Anthony Vidler, no seu livro Histórias do Presente Imediato. Em que medida essas compreensões da história, por meio do distanciamento necessário do tempo, como considera Panofsky, se relacionam, onde se diferenciam? Desse embate resulta uma atualidade crítica do pensamento de Alberti no sentido de que ele fomenta a liberdade da história como narrativa. Porém, ele a restringe a uma natureza mítica. De modo diferente, uma abordagem contemporânea, como a de Vidler, reclama por uma revisão crítica dos ícones modernistas, estimulando a busca pelos problemas não resolvidos da modernidade, que por hoje respondemos na cidade. Formam-se, assim, duas searas de investigação fundamentais:

1) a primeira, sobre: como a história era apresentada na tratadística renascentista? Como era trabalhada essa relação entre projeto e história no momento de inauguração da modernidade, de acordo com Manfredo Tafuri? Isto é, no Renascimento? Para desenvolver essa questão, este artigo propõe trabalhar o conceito de bistoria dentro de escritos de Leon Battista Alberti, mais especificamente a partir de Da Pintura, na inauguração da grande narrativa ocidental da modernidade.

2) A segunda seara de pesquisa consiste num questionamento que se dirige para a historiografia contemporânea: como, após o ar-

100 O texto original foi traduzido para o português brasileiro por Antônio da Silveira Mendonça, para integrar a edição de 1999, da Editora da Unicamp. LEON BATTISTA ALBERTI, Da Pintura, Campinas, Ed. da Unicamp, 1999. 
refecimento do historicismo pós-moderno, e num momento de consenso de esgotamento da narrativa ocidental da modernidade representada pela morte da arte, segundo Arthur Danto, como se aborda o tempo, e o seu acúmulo no espaço arquitetônico? Para tal análise, será utilizada a produção crítica de Anthony Vidler, mais especificamente seu livro Histories of the Immediate Present, referência crítica contemporânea no qual essa questões são trazidas.

A hipótese que se levanta é a de que há evidentemente diferenças fundamentais entre a postura desses autores já que são olhares de arquitetos ou pensadores do espaço de momentos históricos muito diferentes. Mas ainda assim o pensamento de Alberti é muito atual quando ele atribui liberdade narrativa para história. Vidler de certo modo atualiza esse pensamento, ao alargar sua compreensão para além da natureza mítica. Por isso ele acredita que é preciso procurar na história pelos problemas não resolvidos, as pontas soltas da modernidade, as quais hoje não sabemos amarrar e nos explodem nos nossos problemas urbanos contemporâneos. Seria possível esse anacronismo, essa atualidade do entendimento de Alberti da história mesmo considerando contextos tão diversos? Da confrontação do conceito de historia em Alberti, na inauguração da modernidade, com conceito de pos-história, como apresenta Anthony Vidler, no seu livro de 2008, existe continuidade?

Os objetivos principais deste trabalho são dois: 1) primeiro, por meio de uma investigação no conceito de história no Da Pintura de Leon Battista Alberti, pretende-se compreender que tipo de relação com o passado, o presente e o futuro predominava na construção do espaço arquitetônico durante este momento - o renascimento italiano - inaugural da modernidade, como defende Manfredo Tafuri; momento quando, segundo Arthur Danto, inicia-se uma determinada narrativa histórica da arte. 2) o segundo objetivo é avaliar, segundo as considerações de Anthony Vidler, em Histórias dos Presente Imediato, o entendimento contemporâneo de história segundo um crítico de arquitetura. Assim podemos avaliar a atualidade do pensamento de Alberti diante das mudanças fundamentais 
do imaginário social nesses extremos da narrativa mítica da modernidade. Pretende-se também, assim, contribuir na investigação sobre o estatuto da história na sociedade contemporânea.

\section{Alberti e a historia}

A partir do Renascimento Italiano especialmente, inicia-se um processo de emancipação da profissão de arquiteto. O arquiteto passa a ser reconhecido dentro do campo das artes liberais (e não mais das artes mecânicas, como ao longo do Medievo). Contribuiu para isso o advento de novas técnicas de representação, como a perspetiva, que tornou possível a prefiguração dos objetos arquitetônicos em totalidade. Essa possibilidade representacional viabilizou ainda um maior descolamento das atividades de projetar e construir, isto é, do projeto e do ambiente físico de produção do espaço (canteiro de obras).

$\mathrm{O}$ advento da perspetiva foi um fator determinante também para o surgimento das ilustrações de cidades ideais com suas formas ideais, seus ordenamentos ideais, suas proporções ideias. Esses projetos foram um tema caro aos renascentistas e dentre eles destacam-se as telas de cidades ideias, como aquelas hoje localizadas em Urbino (1480-1490), na Galleria Nazionale delle Marche; em Baltimore (1470-1480), no Walter Arts Museum, e em Berlim, na Gemäldegalerie.

Dentre os tratados do século XV, Leon Battista Alberti escreveu sobre o tema da "história" no seu tratado Da Pintura. Neste tratado, Alberti fornece modos de como o artista deve proceder para realizar a pintura "como imitação e representação de coisas e figuras em suas corretas relações espaciais, [de onde] nasce a famosa visualização da pintura como uma janela através da qual o espectador olha, de uma determinada distância, a cena que se lhe apresenta." 101 Nesse sentido, suas considerações sobre a "história" aparecem como um aspeto fundamental para que o pintor tenha êxito na sua obra. E Alberti estende essas considerações ao artista

101 GRAYSON in LEON B. AlBERTI, Da Pintura, Campinas, Ed. da Unicamp, 1999, p. 59. 
construtor, o arquiteto - que passa a artista liberal no Renascimento Italiano, conforme explicado anteriormente.

Para Alberti, como explica Carlos Brandão ${ }^{102}$, era necessário ao artista combater a "alienação estética", ao colocar a arte com uma função pedagógica dedicada ao desenvolvimento de "um mundo mais justo e mais feliz" - ao que o autor chama de bene beateque vivendum. A atribuição de uma responsabilidade pública pedagógica à arte exigiu, portanto, abrir este universo de modo a relacioná-lo com "outros campos da cultura, particularmente com as litterae e a herança clássica promovidas no início do século XV. E, sobretudo, conectar esses conteúdos renovadores às novas formas de expressão que Giotto, Masaccio, Brunelleschi e Donatello haviam elaborado"103.

Alberti se utiliza de alguns operadores conceituais importantes que atuam no processo de "liberação" ou "liberalização" da arte arquitetura, isto é, que atuam na instituição da arquitetura na sociedade como um campo de manifestação fundamentado na cultura letrada - por isso, passa a ser considerada, como a pintura, a escultura, a música e a poesia, como artes liberais e não mais mecânicas. A liberação da arquitetura como arte no Renascimento reforça o corpo das artes liberais que se fundamentam na premissa de arte como produto de elaboração intelectual do homem sobre a natureza. É uma liberação é marcada no Renascimento pela alteração da consciência do que significa arte, do sujeito artista e de seu papel na sociedade.

Segundo Arthur Danto ${ }^{104}$, é nesse momento do século XV quando se inicia uma determinada narrativa histórica da história da arte, que é marcada pela consciência da arte e seu posicionamento diferenciado na sociedade. Isso só é possível por meio dessa diferenciação das artes como meio de expressão de genialidades criadoras. O que marca o fim desta narrativa, como afirma Danto, é justamente o surgimento de uma consciência do encadeamento histórico das manifestações artísticas dentro de uma determinada fase de manifestação das imagens que, para Danto,

102 CARLOS BRANDÃO, Quid Tum? O Combate da Arte em Leon Battista Alberti, Belo Horizonte, UFMG, 2000, p. 136-140.

103 CARLOS BRANDÃO, op. cit, p. 137.

104 ARTHUR DANTO, After the End of Art: Contemporary Art and the Pale of History, Princeton, Princeton University Press, 1997, p. 3-20. 
chegou ao fim. Não é a morte da arte o que Danto pontua, mas o fim desta determinada narrativa histórica que teria se iniciado no século XV para findar na década de 60, do século XX. Pode-se dizer que Alberti pertence à geração dos fundadores dessa narrativa histórica da arte, a Modernidade - na visão de Danto (ARTHUR DANTO, A transfiguração do lugar comum, São Paulo, Cosac Naify, 2005, p.4) - e como tal contribuiu na divulgação dessa nova consciência, no Renascimento Italiano. Essa consciência favoreceu a alteração do estatuto da arquitetura, ao deixar de ser artes mecânicas e passar a ser pensada como artes liberais. E como tal ela cumpre, dentro do sistema renascentista, uma função educadora da moral e do exercício das virtudes humanistas.

Nesse contexto, a "história" é um dos operadores conceituais que Alberti trabalha para fundamentar a arte liberal, portanto, também a arquitetura, como produto de uma razão pensante, que transforma a natura naturata em natura naturans. História para Alberti é a grande obra do artista. No tratado Da Pintura, ele relata:

A maior obra do pintor não é um colosso, mas uma história. A história proporciona maior glória ao engenho do que o colosso. Os corpos são parte da história, os membros são partes dos corpos, a superfície é parte dos membros, portanto as primeiras partes da pintura são as superfícies. Da composição das superfícies nasce aquela graça nos corpos a que chamamos beleza. ${ }^{105}$

Para Alberti as partes que compõem a história são os corpos, cujas partes são os membros, cujas partes são as superfícies. Superfícies pictóricas as quais, por sua vez, fazem os membros, os quais compõem os corpos, os quais se relacionam numa história: numa narrativa moral que contextualiza a obra final do pintor num sistema de valores mais amplo, que é aquele do pensamento humanista. Com essa proposição, Alberti fundamenta a liberação das artes atribuindo ao pintor a responsabilidade de atuar na construção de dramas que cumpram a função educadora na paidéia, no sistema moral, religioso e cultural da sociedade; ao pintor é atribuída uma função pedagógica - mas não doutrinária, como no

105 LEON BATTISTA ALBERTI, Da Pintura, Campinas, Ed. da Unicamp, 1999, p.114. 
Medievo - por meio da história que ele narra. A composição da imagem (compositio) é dotada de um equilíbrio do jogo entre as partes (concinnitas) e é regulada pela história, pelo drama que "define a disposição dos corpos, membros e superfícies."106 A história é o drama no qual estão envolvidas as figuras que compõem a imagem.

"A história, merecedora de elogio e admiração, deverá com seus atrativos se apresentar de tal forma ornada e agradável que conquistará, pelo deleite e movimento de alma, a todos que a contemplem, doutos e indoutos. A primeira coisa que proporciona prazer na história provém da variedade e copiosidade das coisas. [...] Para mim é muito copiosa a história em que em seus lugares se misturam velhos, jovens, meninos, mulheres, meninas, criancinhas, frangos, gatinhos, passarinhos, cavalos, ovelhas, construções, províncias e todas as coisas semelhantes. Louvarei toda e qualquer riqueza que pertença à história."107

A história assume, portanto, um papel regulador na composição da pintura, vista como narrativa humana, tema mítico, que se desenvolve dentro de um determinado recorte - janela (frame) que se abre no retângulo da superfície pictórica. Ela determina as relações entre os elementos pictóricos do quadro. Nesse sentido, trata-se de uma mimesis da ação humana, e não propriamente na natureza no seu estado natural. A ação humana transforma essa natureza, e é isso que diferencia os conceitos de natura naturans e natura naturata no Renascimento Italiano. Portanto, o naturalismo de Alberti, como explica Cecil Grayson, é metodológico e, nesse sentido, se aplica, portanto, "à representação do tema a ser pintado. Esta 'história' será inspirada provavelmente na "leitura de poetas e escritores, com os quais compartilhará o relato de alguma ação"108.

Brandão sugere que Alberti resgata o conceito de "história" da Retórica de Cícero, para quem este conceito funciona como "guia para o futuro".

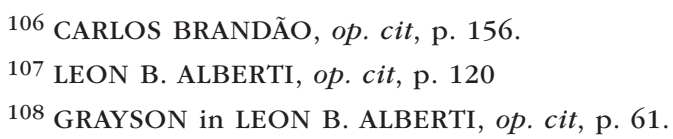


"Considerada como o maior instrumento da Retórica por Cícero, ela [a história] serve de guia para o futuro e é como tal que Alberti resgata-a para a Pintura. Nela os eventos não são apenas descritos, mas entendidos dentro de um contexto, recompostos na trama do intérprete que refaz a ligação entre os fatos dando-lhes nova forma."109

Para Alberti, portanto, a pintura torna-se "instrumento da mensagem histórica”. Contudo, se ele propõe que a história tenha autonomia reguladora dentro da representação artística, ele, no entanto, a submete hierarquicamente à ética humanista do Renascimento. Essa relação legitimou, por exemplo, outros humanistas do mesmo período, como Leonardo Bruni, a conceberem a história como uma narrativa mítico-fatual. A história estabelece-se, assim, como uma trama de encadeamentos cruzados entre tempos, espaços e pessoas que compreende os arquétipos de ações e gestos a serem utilizados na construção do discurso desejado. Ela quase se aproxima da poesia, se as duas não tivessem sido separadas, desde Aristóteles, como explica Arthur Danto $^{110}$. No Renascimento de Alberti, esses campos se aproximam, mas não se coincidem, porque, ainda que, ao aparecer como narrativa mítico-fatual, a história se pretenda modelar e universal como a poesia, ela está presa a uma entidade particular - que pode ser uma cidade, como Roma ou Florença, por exemplo. Como construção narrativa, ela é ferramenta do discurso, da retórica, emprestada de Cícero à atividade do pintor, por Alberti. O discurso que se pretende divulgar, no entanto, não é mais aquele religioso do Medievo, mas aquele da ética humanista. O pintor está a serviço desse projeto social e cultural, dentro do qual sua obra deve "adequar-se à mensagem e ao comportamento suscitados na alma" do cidadão ${ }^{111}$.

Descrente dos filósofos de sua época, ele concede à arte esse papel de porta-voz da história, pensando a arte como o meio de expressão dos valores morais e éticos do seu projeto humanista. Alberti entende que esse lugar importante reservado à história dentro do seu tratado sobre

109 CARLOS BRANDÃO, op. cit, p. 157.

110 ARTHUR DANTO, A transfiguração do lugar comum, São Paulo, Cosac Naify, 2005, p. 119 111 CARLOS BRANDÃO, op. cit, p. 161. 
a pintura vale igualmente à arte de edificar. Ao modo do pintor, seria também um grande feito do arquiteto, para Alberti, reconhecer dentro do discurso humanista sobre a cidade renascentista uma história, uma narrativa urbana na qual o arquiteto deva inserir sua obra em perspetiva com o tempo histórico-mítico da tradição humanista. $\mathrm{E}$, de repente, na visão de Alberti, é como se a cidade se tornasse um grande texto. Assim, a solução de Filippo Brunelleschi para o domo de Santa Maria das Flores é costurada dentro de um discurso ético mais amplo, na qual ela cumpre uma função civilizadora na sociedade, e as decisões técnicas do autor do projeto corroboram na produção desse espaço civilizador. Uma obra de arquitetura que esteja fora dessa narrativa pedagógica a serviço do projeto ético humanista constitui-se como manifestação do que Alberti denomina, segundo Brandão, a hybris, a mania de construir do arquiteto. "Alberti entrelaça e dimensiona, reciprocamente, Ética e Estética, com vistas à realidade que seu humanismo projetava."112

Ao ser entendida como linguagem cuja mensagem é utilizada na educação da sociedade, resta atribuir à arte e à arquitetura uma gramática e uma sintaxe. É o que Alberti vai propor. A gramática e a sintaxe próprias das artes constituem-se em proporções, relações e medidas, métodos e sistemas de mensuração, os quais Alberti trabalha nos tratados e que determinam o campo de criação do artista. São normatizações que tornam a obra reconhecível ao compartilhar dos códigos utilizados para aquele projeto de sociedade. A linguagem clássica, o antropomorfismo, as regras de composição do espaço, aspetos que caracterizam a arquitetura renascentista e albertiana, são legitimados ao funcionarem como estratégias que contribuem na divulgação do discurso da ética humanística. Nesse sentido, o conhecimento do passado é determinante para conceção dessa linguagem, já que ela estabelece uma relação direta, também visual, com a tradição clássica.

Contemporâneo a Alberti, o humanista Leonardo Bruni também concebe a história como essa narrativa mítico-fatual ao unir a fundação de Florença à tradição clássica, atribuindo, sem fundamentos causais suficientes, raízes romanas e etruscas ao povo florentino. Essa foi uma estratégia retórica

112 Ibidem, p. 161. 
utilizada no seu discurso para convencimento da população ao engajamento no seu projeto político e ético para Florença. Newton Bignotto comenta sobre um dos textos de Bruni, Oratio, publicado em 1428: é "uma peça retórica, no entanto, fica claro que o objetivo do texto é ligar Florença a uma velha tradição, e assim, fazer de Nanni degli Strozzi um exemplo à altura dos que no passado arriscaram suas vidas pela pátria."113

Em "Oratio", segundo Bignotto, Bruni relaciona as origens de Florença aos etruscos e aos romanos. Florença apresenta ao mesmo tempo autonomia em "relação aos vizinhos e formações políticas", como o faziam os etruscos, e também poder de expansão territorial e propagação das artes e letras, como nos romanos. Sobre essa descendência romana, Bignotto explica que ela foi fator importante para justificar o desejo de expansão da cidade, porque "de fato, os florentinos, em momento algum de sua história do século XV, abriram mão de uma posição política de liderança na Itália, o que implicava na legitimação do seu desejo de conquista de novos territórios, como fizera Roma em seu tempo.” ${ }^{114}$ Ferramentas dessa expansão política que gerava fortalecimento econômico, as artes e as letras fortaleceram a autonomia e a liderança de Florença no Renascimento Italiano, especialmente pela valiosa contribuição desta cidade "para a restauração da língua latina e para o Renascimento do grego, o que havia garantido o acesso dos italianos aos tesouros do passado, esquecidos ou escondidos pelas péssimas traduções medievais."115

Alberti, compartilhando desse projeto do Renascimento Italiano, acredita que a arte de edificar deva não somente criar espaços para que o drama humano aconteça, isto é, para que a história se desenrole, como ela deve também servir de mediação, meio de expressão desse discurso, pelo seu poder simbólico. Nesse sentido, para Alberti a arquitetura está a serviço dessa história, entendendo história como essa construção narrativa utilizada para legitimar também o próprio projeto do Renascimento Italiano.

113 NEWTON BIGNOTTO, Origens do Republicanismo Moderno, Belo Horizonte, UFMG, 2001, p.142.

114 NEWTON BIGNOTTO, op. cit, p.143

115 Ibidem, p. 143 
Ao mesmo tempo, a história aparece como fonte da linguagem e de amplo repertório formal, logo, trata-se de uma ferramenta de projeto nas mãos do arquiteto. Para Alberti, longe de ser um problema, a história era uma solução para a disciplina, como sugere Anthony Vidler na apresentação do seu livro The Histories of the Immediate Present. Vidler pondera sobre a questão da utilidade da história na sua relação com o projeto ao colocá-la como uma questão relativamente recente. Segundo ele, "para maior parte da história da arquitetura, história não era um problema para a arquitetura - ou antes de ser um problema per se, as questões em torno da história eram na verdade solução para a disciplina."116 A partir do momento em que a tradição medieval passou a ser gradual e conscientemente substituída pela linguagem utilizada na Antiguidade, a história é que supriu o material próprio à criação arquitetônica. Nesse sentido, na maioria das vezes, quase sem exceção, o historiador da arquitetura era o próprio arquiteto que misturava sua teoria à escrita da história, essa narrativa resultante de uma mistura de fatos e evidências com componentes míticas e universalizantes, e que não raro legitimava sua produção arquitetônica.

\section{Anthony Vidler e depois da bistoria}

Entre as obras recentes sobre história da arquitetura, Anthony Vidler escreveu Histories of the Immediate Present, publicação pelo MIT Press, em 2008, derivada de sua tese de doutoramento. Na apresentação, Peter Eisenman sugere que o trabalho de Vidler busca explorar como a história e os historiadores do modernismo poderiam ser interpretados e escritos depois da crítica pós-estruturalista aos limites disciplinares, já que esses mesmos limites é que tradicionalmente instituíram as grandes figuras e movimentos da história.

O objetivo é entender o trabalho de historiadores do pós-segunda guerra na tentativa de criar uma narrativa coerente de desenvolvimento

116 ANTHONY VIDLER, Histories of the Immediate Present, Princeton, Princeton University Press, 2008, p.3 
do modernismo, relacionando aquele tempo com as vanguardas do princípio do século XX. Nesse sentido, Vidler está interessado é em como as histórias do modernismo se adaptaram para abrigar a teoria e a prática daquele tempo.

É importante o trabalho de Vidler de uma reavaliação das histórias produzidas sobre o modernismo também na medida que ele acaba por tocar questões centrais sobre o historiador da arquitetura e sua relação com o arquiteto. "Que tipo de trabalho a história da arquitetura deve fazer para a arquitetura e especialmente para a arquitetura contemporânea? Este é claramente uma versão do corriqueiro refrão 'como a história se relaciona com projeto? É algo útil? E se sim, em quais sentidos?”117

Neste livro, Vidler trabalha a história da modernidade, o entendimento de suas origens e suas margens a partir de quatro autores que sugerem quatro abordagens do modernismo: Emil Kaufman e o modernismo neoclássico; Colin Rowe e modernismo maneirista; Reyner Banham e o modernismo futurista; e Manfredo Tafuri e o modernismo renascentista. Vidler coloca em discussão a historiografia da arquitetura moderna a partir desses quatro autores e no embate desses pensamentos diversos, ao mesmo tempo convergentes e divergentes, ele sugere provocadoramente que a história em algum sentido completou-se e ao futuro só resta, portanto, a repetição.

"Dizer, como Kaufman o fez, que o Iluminismo e suas geometrias da razão eram formas do moderno eterno, ou como Rowe, que as ambiguidades do modernismo estavam de algum modo reemergindo no modernismom ou como fez Branham, que a história construiu uma trajetória para si mesma que pode ser inscrita no seu 'futuro', ou finalmente como fez Tafuri, que o modernismo foi simplesmente o resultado final de uma quebra epistemológica entre medievo e renascença, foi dizer que a história tinha em algum sentido chegado a sua completude. Se

117 Tradução minha. Original: What kind of work does or should architectural history perform for architecture and especially for contemporary architecture? This of course is a version of the commonplace refrain, How is history 'related' to design? Is it 'useful'? And if so, in what ways? In ANTHONY VIDLER. Histories of the Immediate Present. Inventing Architectural Modernism. Cambridge: MIT Press, 2008, p. 3. 
o fim podia ser previsto, ou tinha de fato chegado, então o futuro era para ser daí pra frente não mais que repetição."118

Vidler explica que a ideia de pós-história foi sugerida inicialmente pelo matemático do século XIX, Antoine-Augustin Cournot, não se caracterizando então propriamente como um conceito, mas como uma seara de discussão de temporalidades. "Posthistoire foi aplicado no momento quando a criação humana (seja uma instituição ou um objeto) alcançou um estado no qual já não existia mais possibilidade de desenvolvimento além - quando tudo o que poderia ser feito seria o seu eterno aperfeiçoamento." ${ }^{119}$ Para Cournot, a pós-história é uma fase posterior às fases pré-histórica e histórica e ela consiste no ponto final inevitável de todas as culturas, como já demonstrado, segundo o autor, pela "natureza estática da burocrática sociedade chinesa ao longo do último milênio"120. A ideia de pós-história, no entanto, ao contrário do que pode parecer, era então uma conceção extremamente historicista, inevitavelmente resultante do próprio pensamento histórico. Mas essa ideia foi recebida e transformada no século XX de um modo menos historicista e mais contra-histórico, sendo utilizada por abordagens "finalistas" de intelectuais de 1930 e $1940^{121}$. Vidler cita o filósofo belga Hendrick de Man como fundamentador dessa linha de pensamento, que é o pensamento pós-histórico:

"O termo pós-histórico parece adequado para descrever o que acontece quando uma instituição ou uma conquista cultural cessam de ser

118 Tradução minha. Original: To imply, as Kaufman did, that the Enlightment and its geometries of reason were forms of the eternal modern, or as Rowe did, that the ambiguities of manneirism were in some way reemergent in modernism, or as Banham did, that history constructed a trajectory for itself that might be graphed into its 'future', or finally as Tafuri did, that modernism was simply the end result of an epistemological break between the medieval and Renaissance worlds, was to imply that history had in some sense come to completion. If the end might be predicted, or indeed had arrived, then the future was to be bereft of all but repetition. In.: VIDLER, Anthony. Op.cit, p.194.

119 ANTHONY VIDLER, Histories of the Immediate Present, Princeton, Princeton University Press, 2008, p.194. Tradução minha.

120 Ibidem, p. 194. Tradução minha.

121 Ibidem, p. 195. 
historicamente ativas e produtoras de novas qualidades, tornando-se puramente recebedoras ou ecleticamente imitativas. Isso posto a noção de Cournot de pós-história se adequaria... à fase cultural que, seguindo o 'excesso do sentido', tornou-se 'ausência de sentido'. A alternativa então é, em termos biológicos, ou a morte ou a mutação." ${ }^{122}$.

Foi uma ideia importante para se colocar em xeque as tendências historicistas dominantes no século XIX e especialmente apropriada à história da arte, considerando-se a ideia de aperfeiçoamento do modo de fazer, de produzir por meio de desenvolvimento estilístico e funcional, concepções também próprias a algumas tendências da Beaux-Arts do século XIX. Em Gianni Vattimo, pós-histórico torna-se "o simples reconhecimento do mundo moderno como ele é - um mundo de mudança sem mudança, de mutabilidade sem mutabilidade - e então pós-história é um conceito que permite descrever as experiências do fim da história.”123

Vidler sugere que o pós-modernismo na arquitetura é um momento especial do pensamento pós-histórico ou um caso especial desse tipo de pensamento traduzido para a arquitetura. Ele levanta a questão do que fica, então, para o pensamento histórico e para a modernidade concebida historicamente.

Se as questões que hoje se levantam ainda são questões modernas, já que o contemporâneo está ainda envolvido nesse discurso moderno, e se modernidade é esse projeto de reavaliação e renovação constantes, não é mais possível abordar a história da arquitetura moderna em busca de classificar estilos ou movimentos. É preciso percorrê-la de outro modo, e são esses outros modos que se pretende fomentar e empreender. Menos em busca de aspetos legitimadores de ambiciosos projetos presentes ou de vocabulário formal, e mais em busca do desdobramento das ações e contextos, especialmente aqueles inconclusos e aberto, pela natureza conflitante que os determina.

122 Tradução minha. Original: The term posthistorical seems adequate to describe what happens when an institution or a cultural achievement ceases to be bistorically active and productive of new qualities, and becomes purely receptive or eclectically imitative. Thus understood Cournot's notion of the posthistorical would... fit the cultural pabse that, following a 'fulfillment of sense', has become 'devoid of sense'. The alternative then is, in biological terms, either death or mutation. In: ANTHONY VIDLER. Op.cit., p. 195.

123 Ibidem, p.196. 


\section{Entre a narrativa mítica e a eterna repetição}

Da narrativa mítica proposta por Alberti à eterna repetição determinada pelo pensamento pós-histórico, a história é uma invenção, porém uma invenção antes presa dentro de um projeto ético e depois esvaziada pela sua "alegorização". Se nas margens renascentistas, a história, para Alberti, era uma construção mítica a serviço de um projeto ético e social, nas margens da pós-modernidade o pensamento pós-histórico fez do progresso uma rotina e tornou inevitável a desilusão que se segue frente à narrativa libertadora com que se fiou a modernidade. O que se propõe, evitando fechamentos e neo-finalismos, é que contra as preconcepções estabelecidas sobre a história da arquitetura moderna seja estimulada a reabertura da própria consciência histórica do sujeito, pensando que dentro do campo de ação do arquiteto, essas consciência e suas franjas é que trabalham na atualização dos limites de ação desse profissional.

Existe na abordagem que Vidler propõe para a história da arquitetura uma consciência do conflito, que é interno à própria natureza da atividade arquitetônica, mas ao mesmo tempo uma busca pelos seus desdobramentos, pelas in-soluções, pelo que ainda está para ser ou em estado de vir a ser na própria história - no presente, no passado e no futuro.

"A história da arquitetura moderna deve procurar (...) por lugares onde as inconfortáveis questões de forma e programa com respeito à sociedade e sua formação política foram colocadas; onde uma irresolução, melhor que uma solução, foi assumida; onde projetos começaram mas foram deixados inacabados, não por fracassos mas como desafios ativos e insolúveis; onde irrupções de desde fora do campo inconvenientemente questionaram a validade das práticas estabelecidas; onde as próprias formas de conceber a história ela mesma foram colocadas em xeque. Precisaríamos reencontrar momentos e figuras de interrupção (...) e seriamente reavaliar as sagradas vacas da modernidade, cujo trabalho tornou-se muito rapidamente canônico a fim de detectar as inconsistências internas (...) precisaríamos abrir as ideias de 'modernismo' tão prevalecentes depois da segunda guerra mundial."124

124 Tradução minha, com cortes do texto original. Original completo: The history of modern architecture would (...) look for places where the uncomfortable questions of form 
Essa abordagem coloca em xeque a totalidade necessária à história como ferramenta retórica do humanismo renascentista. Na narrativa de Leonardo Bruni, por exemplo, a conexão com o passado romano, ao contrário de desfilamento dos conflitos, é a criação de uma descendência triunfal para convencer os cidadãos da importância da cidade de Florença. A história é uma invenção, mas uma invenção subjugada a um projeto ético totalizador, visionado por uma determinada classe de intelectuais e poderosos italianos. Uma invenção que muito se aproxima do universalismo da poesia, mas que se distancia dele justamente pela sua ligação a entidades particulares, no caso as cidades de Florença e Roma, por exemplo. Pelas abordagens de Alberti e de Leonardo Bruni, a construção da história - não como campo disciplinar, mas como conhecimento do passado - durante o Renascimento italiano pretende atribuir-se o universalismo da poesia, e por isso ela tem uma matriz mítica. Mas o que ainda a prende é o fato de permanecer como reflexo, ainda que vago, de um tempo, como elucida Danto entre suas explicações sobre imitações e imagens refletidas:

"É possível que Sócrates jamais tenha encontrado uma imitação sem um original, embora, na época em que Aristóteles se apropriou da teoria da mimese, ele já tivesse reconhecido que as imitações devem ser muito diferentes das imagens refletidas num espelho, pois estas estão para as imitações assim como, para citar sua estupenda análise, a história está para a poesia.”125

Para Sócrates, portanto, a história é essa imagem refletida de um real que está fora dela. A poesia tem a liberdade de uma imitação, a mimese

and program with respect to society and its political formation were asked; where irresolution rather than solution was assumed; where projects were started but left unfinished, not as failures but as active and unresoved challenges; where disruptions from outside the field inconveniently questioned the verities of established practices, where the very forms in which we conceive of history istsel have been put into question. We would need to reassess dirsruptive moments and figures, not as curiosities and embarrassments, nor as washed-up utopias (...) but as openings into the process, rather than the appearence, of modernity; we would also need to seriously reevaluate the sacred cows of modernity, whose work has become, too quickly, canonical, in order to detect the internal inconsistencies, the still-open questions lurking behind their monographical façades; finally we would need to open up those ideas of 'modernism' so prevalent after the Second World War." In: ANTHONY VIDLER. Op.cit. p. 199.

125 ARTHUR DANTO, A transfiguração do lugar comum, São Paulo, Cosac Naify, 2005, p.118. 
de Platão, que, como a entende Danto, tem a habilidade da apropriação, da reinvenção, da reescrita. Se em Alberti e Bruni, a história tangencia o poder universal e inventivo da poesia, o pensamento historicista do século XVIII e XIX cuida para que ela se torne uma ciência factível e declara, inclusive, que todo pensamento é histórico na sua essência, mesmo a filosofia. Contra esse historicismo, Nietzsche tece o elogio de que a felicidade consiste na capacidade de sentir a-historicamente, isto é, na duração dos raros momentos de lucidez quase espiritual. É preciso esquecer para manter-se vivo. Para Nietzsche, é condição de sobrevivência de um sociedade se ela deseja mover-se no tempo, e pensar transformações. O que não significa viver sem memórias. É da condição humana, e Nietzsche é enfático na sua defesa, o fardo inadiável de que cedo a criança aprende o que significa a palavra 'foi' e começa a lembrar-se - inicia esse processo cumulativo de construção da própria identidade. Hoje Vidler de certo modo atualiza a capacidade inventiva da história, colocada por Alberti e que é central na abordagem contemporânea proposta pelo crítico inglês. Atualizá-la significa liberá-la da sua função retórica dentro de um projeto ético que se pretende universal - como no renascimento ou mesmo no modernismo - e assumi-la como possibilidade de percurso narrativo que permita acessar com maior variedade os diferentes tempos que circulam no presente. Este pode ser um meio de se chegar mais perto das inúmeras questões abertas e não resolvidas ao longo da modernidade. Não em uníssono dentro de um projeto universal, e tampouco uma história propositora de um modelo de mundo melhor. Mas sim uma abordagem da história da arquitetura como seara de investigação "para desafiar as preconcepções da nossa própria consciência histórica"126.

126 ANTHONY VIDLER, op.cit., p. 200. 